\title{
Management of Travel-Related Infectious Diseases in the Emergency Department
}

\author{
Laura Throckmorton ${ }^{1}$ • Jonathan Hancher ${ }^{2}$ \\ Published online: 6 May 2020 \\ (C) Springer Science+Business Media, LLC, part of Springer Nature 2020
}

\begin{abstract}
Purpose of Review Emergency physicians generally have limited exposure to internationally acquired illnesses. However, travelers can present quite ill, and delays in recognition and treatment can lead to increased morbidity and mortality. This paper aims to summarize typical presentations of common international diseases and provide the emergency physician with a practical approach based on current guidelines.

Recent Findings In the treatment of traveler's diarrhea, azithromycin has become the treatment of choice due to the growing antibiotic resistance. Intravenous artesunate was approved in 2019 under investigational new drug protocol for the treatment of severe malaria, and artemisinin-based combination therapies (ACTs) have become the first-line treatment for most cases of uncomplicated malaria. Since the 2015 outbreak, Zika has become a concern to many travelers, but the current treatment is supportive.

Summary Clinicians should be aware of a few noteworthy updates in the treatment of internationally acquired illnesses, but more importantly, they must recognize warning signs of severe illness and treat promptly. Future research on workup and disposition could help emergency physicians identify which patients need admission in well-appearing febrile travelers.
\end{abstract}

Keywords International infectious diseases $\cdot$ Traveler's diarrhea $\cdot$ Febrile traveler $\cdot$ Emergency department $\cdot$ Malaria $\cdot$ Global Health

\section{Introduction}

While variable by practice setting, most emergency physicians in the USA have little regular exposure to internationally acquired illnesses. Therefore, their ability to recognize these illnesses can be limited. While basic practice guidelines are available, confirmatory diagnostic testing in the emergency department is limited, and some treatments might not be readily available. This article aims to assist the emergency

This article is part of the Topical Collection on Infectious Disease

Laura Throckmorton

LThrock22@gmail.com

Jonathan Hancher

jonathanhancher@gmail.com

1 Center for Emergency Medicine, University Hospitals Cleveland Medical Center, 11100 Euclid Ave., Cleveland, OH 44106, USA

2 Department of Emergency Medicine, University of North Carolina Hospitals, University of North Carolina, Physician Office Building, 170 Manning Drive, CB\# 7594, Chapel Hill, NC 27599-7594, USA physician identify internationally acquired illnesses based on travel history, signs, and symptoms and to help guide management based upon current guidelines and their practical applicability in the emergency department.

\section{Prevention}

While the emergency physician is unlikely to be providing pre-travel care in the USA, many EM physicians travel internationally and therefore need to be aware of primary prevention strategies for themselves and patients they treat while abroad. Country-specific guidelines are published by the Centers for Disease Control (CDC), but general considerations include vaccination, prophylactic antibiotics, and protection from insect bites or infected water sources.

\section{Mosquito-Borne Illnesses}

- Bite prevention: Travelers to areas with malaria, Zika virus, and other mosquito-borne illnesses can minimize their 
risk by wearing long sleeves and pants, using bed netting, minimizing outdoor activities around dusk, and avoiding travel during the rainy season [1].

- Chemoprophylaxis: Medication selection should be guided by local resistance as well as patient preferences in timing of travel, side effects, and medical history. Table 1 outlines the medications currently approved in the USA for malaria prophylaxis and specific considerations for each medication.

- Standby emergency treatment (SBET): While chemoprophylaxis is the most efficacious in malaria prevention, SBET has also become an option for travelers who are traveling to low-risk areas who do not want to take chemoprophylaxis for the duration of their travel. Patients using this method should begin taking prescribed antimalarials if they develop a fever and seek a medical evaluation as soon as possible.

\section{Vaccinations}

- Hepatitis A [3]: Recommended before most international travel at least 4 weeks prior to departure

- Second dose after 6 months for long-term immunity

- Typhoid fever [4]: Recommended before most international travel and can be administered via oral capsules or injection

- Particularly important due to rising antibiotic resistance of S. typhi
- Little to no efficacy against $S$. paratyphi

- Live, attenuated vaccine: Oral capsule taken every other day for 4 days to be completed at least 1 week prior to departure

Must be kept refrigerated and consumed $1 \mathrm{~h}$ prior to a meal

Cannot be given to immunocompromised patients

Booster needed every 5 years

- Inactivated vaccine: Single-dose intramuscular injection given at least 2 weeks prior to departure

Booster needed every 2 years

- Dengue vaccine (Dengvaxia) [5]: Approved in May 2019 by the FDA for children ages 9-16 living in areas where dengue is common (American Samoa, Puerto Rico, US Virgin Islands) who have laboratory-confirmed prior dengue infection

- Increased risk of severe dengue with subsequent exposure if given to naïve patient

- Available through age 45 in many endemic countries

- Three doses spaced every 6 months

\section{General Approach to the Febrile Traveler}

When treating a febrile patient with a history of travel, important considerations include travel location, timing, sick contacts, weather, activities partaken while abroad, pregnancy, and medical comorbidities. Many infectious diseases acquired

Table 1 Malaria chemoprophylaxis

\begin{tabular}{|c|c|c|c|}
\hline & Dosing & Pregnancy & Special Considerations \\
\hline $\begin{array}{l}\text { Atovaquone- } \\
\text { proguanil }\end{array}$ & $\begin{array}{l}\text { - Daily dosing } \\
-1-2 \text { days before through } 7 \text { days after }\end{array}$ & - Contraindicated & $\begin{array}{l}\text { - Side effects uncommon } \\
\text { - More expensive }\end{array}$ \\
\hline Chloroquine & $\begin{array}{l}\text { - Weekly dosing } \\
\text { - } 1-2 \text { weeks before through } 4 \text { weeks after }\end{array}$ & $\begin{array}{l}\text { - Safe in all } \\
\text { trimesters }\end{array}$ & - Many areas with resistance \\
\hline Doxycycline & $\begin{array}{l}\text { - Daily dosing } \\
\text { - 1-2 days before through } 4 \text { weeks after }\end{array}$ & $\begin{array}{l}\text { - Likely safe but } \\
\text { second line }\end{array}$ & $\begin{array}{l}\text { - Photosensitivity } \\
\text { - Inexpensive } \\
\text { - Can also prevent rickettsia and leptospirosis }\end{array}$ \\
\hline Mefloquine & $\begin{array}{l}\text { - Weekly dosing } \\
\text { - } 2 \text { weeks before to } 4 \text { weeks after }\end{array}$ & $\begin{array}{l}\text { - Safe in all } \\
\text { trimesters }\end{array}$ & $\begin{array}{l}\text { - Some areas of resistance } \\
\text { - Not recommended for psychiatric conditions, } \\
\text { seizures, cardiac conduction abnormalities }\end{array}$ \\
\hline Primaquine & $\begin{array}{l}\text { - Daily dosing } \\
\text { - 1-2 days before through } 7 \text { days after }\end{array}$ & - Contraindicated & $\begin{array}{l}\text { - Used in areas of }>90 \% \text { prevalence of } P \text {. vivax } \\
\text { - Contraindicated in G6PD deficiency }\end{array}$ \\
\hline $\begin{array}{l}\text { Tafenoquine } \\
\text { (newly FDA } \\
\text { approved in } \\
\text { 2018) }\end{array}$ & $\begin{array}{l}\text { - Daily dosing for } 3 \text { days before travel and transitions to } \\
\text { weekly through } 1 \text { week after return }\end{array}$ & - Contraindicated & - Contraindicated in G6PD deficiency \\
\hline
\end{tabular}

Source: CDC [2] 
abroad can also take several weeks to manifest. Practitioners should remember to test for common local illness, particularly influenza during flu season, and cover for a broad range of illnesses in toxic-appearing patients.

Workup is dependent on location and timing of travel to help determine which diseases are most likely. For cases in which many pathogens seem possible, we would recommend lab workup to include complete blood count with differential, basic metabolic panel; liver function tests; coagulation screen; blood smear; CK level; pregnancy test; influenza swab; blood cultures; urinalysis; urine culture; and chest $\mathrm{x}$-ray. While many findings are nonspecific, these tests will likely identify patients with warning signs of severe illness and might help guide the practitioner toward the most likely pathogen.

Many internationally acquired illnesses cannot be definitively diagnosed in the emergency department given the similar features of many diseases and the delay in diagnostic results. In determining disposition, clinicians should consider warning signs of severe disease for the most likely cause of illness, and if present, admit. Many febrile illnesses can be managed in the outpatient setting, but patients should be given strict return precautions and close follow-up. If the patient has a travel history which places him or her at risk of dengue, NSAIDs should be avoided until it has been definitively ruled out due to the risk of progression to dengue hemorrhagic fever.

\section{Malaria}

\section{Epidemiology and Transmission}

Malaria is the most common febrile illness among travelers to endemic areas and is caused by the mosquito-borne parasites of the Plasmodium genus, primarily P. falciparum, $P$. vivax, $P$. ovale, and $P$. malariae. Cases in the USA have been increasing over the last few decades to over 2000 cases reported to the CDC in 2016. The majority of cases diagnosed in the USA are among travelers returning from Africa, particularly West Africa. P. falciparum has been identified in nearly $70 \%$ of infections with $P$. vivax being the second most common. Mortality in the USA is $<0.5 \%\left[6^{\circ}\right]$.

\section{Signs and Symptoms}

Symptoms of malaria include fever, headache, chills, diaphoresis, myalgias, diarrhea, vomiting, and cough. The onset of symptoms is dependent on the Plasmodium species with $P$. falciparum typically causing the most severe symptoms. In confirmed cases in 2016 , over $90 \%$ of those with P. falciparum reported onset of symptoms within 1 month of returning to the USA [6•]. However, nearly half of cases of $P$. vivax or $P$. ovale had onset of symptoms more than 1 month after returning to the USA likely due to reactivation of dormant liver parasites [6•]. Febrile seizures can occur in children but should be considered a warning sign of cerebral malaria in any age group.

Severe malaria definitions vary between the CDC and the World Health Organization (WHO), but diagnosis can be made with any of the following signs and symptoms [7, 8, 55]:

- Seizures, altered mental status, or other neurologic manifestations

- Acute kidney injury

- Hemoglobin $<7 \mathrm{~g} / \mathrm{dL}$

- ARDS

- Hypoglycemia $(<40 \mathrm{mg} / \mathrm{dL})$

- Acidosis

- Liver failure or severe jaundice

- Hemodynamic instability

- $>$ 5-10\% parasitemia

Of confirmed US malaria cases reported in 2016, approximately $15 \%$ were classified as severe disease, and seven people $\operatorname{died}\left[6^{\circ}\right]$.

\section{Management}

The diagnosis of malaria is typically by blood smear but can also be done by polymerase chain reaction. Additional laboratory abnormalities can include anemia, thrombocytopenia, elevated transaminases, mild coagulopathy, and elevated BUN and creatinine. Lumbar puncture has limited utility in cerebral malaria as results can be normal or show only mild elevations in total protein and cell counts with mildly depressed glucose [9]. If there is any concern for cerebral malaria, the patient should be treated empirically as mortality is high even with treatment.

Recommendations for treatment of malaria are dependent on the presence of any severe features, local resistance, and patient comorbidities. Access to antimalarials in the ED is likely to heavily influence treatment as even many large tertiary referral centers do not have most antimalarial drugs stocked. If the patient took prophylaxis while abroad, a different antimalarial should be selected for improved efficacy and reduced toxicity. The CDC does have a Malaria Hotline (770-488-7788) for treatment assistance with a staff member on call 24/7.

Based on CDC and WHO recommendations, we would recommend the following treatment for confirmed or suspected cases of malaria:

- Uncomplicated malaria $[2,8,10]$

- Artemether-lumefantrine: The only artemisinin-based combination therapy (ACT) approved in the USA

WHO recommends ACTs as the first-line therapy due to highest cure rate. 
- Alternative first-line medications in quinine susceptible areas

Chloroquine

Hydroxychloroquine

- Alternative first-line medications in quinine-resistant areas

Atovaquone-proguanil

Mefloquine

Quinine + tetracycline, doxycycline, or clindamycin

- $\quad$ Pregnancy $[2,8]$

- Artemether-lumefantrine: Approved in 2018 as first-line treatment in second and third trimesters

Second-line drug in first trimester due to limited safety data [11]

- Quinine + clindamycin

- Mefloquine

- $\quad$ Severe malaria $[2,8]$

- First line: Intravenous antimalarials.

Artesunate: First-line therapy for severe malaria but only became available in the USA in 2019 under investigational drug protocol

Not accessible in the ED; must be shipped from CDC Quinidine: Production in the USA discontinued in 2017 [12]

- Second line: Artemether-lumefantrine (oral).

Interim treatment until IV Artesunate can be obtained from the CDC

If unable to swallow pill, NG tube should be placed in ED

- Third line: atovaquone-proguanil or quinine.

- Intravenous clindamycin and doxycycline have been used in the past, but they are not recommended for the initial treatment of severe malaria as the onset of action is greater than $24 \mathrm{~h}$ [2].

Anyone with confirmed $P$. falciparum or species not yet known should be admitted to the hospital [10]. Patients with signs of severe malaria likely need admission to an intensive care unit. Those with no previous history of malaria, immunocompromised patients, children less than five, and pregnant women are at the highest risk for developing severe disease or rapid deterioration, and admission should be strongly considered $[2,13,14]$.

\section{Dengue}

\section{Epidemiology and Transmission}

Dengue is a febrile illness caused by a mosquito-borne flavivirus. It is endemic throughout the tropics and is estimated to cause symptoms in only one quarter of infections. According to the WHO, dengue is the second most common febrile illness in travelers returning from low- or middle-income countries [15]. There are four known serotypes (DEN1-4), and subsequent infection with a different serotype places the individual at higher risk of developing severe dengue.

\section{Signs and Symptoms}

Symptoms generally start 4-7 days following mosquito bite, and the disease consists of three phases $[15,16]$ :

1. Febrile phase

- 3-7 days

- High fevers (40C), severe headache, pain behind the eyes, myalgias, arthralgias, vomiting, lymphadenopathy, rash

2. Critical phase

- $\quad 24-48 \mathrm{~h}$

- Defervescence, capillary leak, hypovolemia, potential development of severe dengue (dengue hemorrhagic fever [DHF] or dengue shock syndrome [DSS])

3. Convalescent phase

- $\quad$ Fatigue lasting days to weeks

\section{Severe Dengue}

Severe dengue (DHF/DSS) is rare and primarily seen in cases of secondary infection with a different serotype. Therefore, severe dengue is particularly uncommon in travelers and should only be expected in those with frequent travel to endemic areas. Nonetheless, severe dengue can be fatal, so awareness of certain features can help distinguish DHF and DSS from other severe febrile illnesses. These findings include pleural effusions, ascites, elevated hemoglobin in the setting of thrombocytopenia, low ESR, hepatomegaly, shock with narrow pulse pressure, petechiae/positive tourniquet test, mucosal bleeding, and DIC [15-17]. 


\section{Management}

Within the first 7 days of illness, diagnosis is made by RT PCR or NS1 antigen testing. IgM antibodies can be detected 47 days after onset of symptoms but can cross-react with other flaviviruses including Zika, West Nile, Yellow Fever, and Japanese Encephalitis [17]. Other laboratory findings include hemoconcentration, thrombocytopenia, leukopenia, and elevated liver enzymes $[15,16]$.

The treatment of dengue, including severe dengue, consists of supportive care, particularly fluid resuscitation, fever control, and management of bleeding. It is important to note that NSAIDS should not be used in the treatment of fever due to the increased risk of bleeding. Platelet transfusions are recommended for platelet counts $<10,000$ in the setting of active bleeding. Prophylactic transfusions are not recommended [18].

Anyone developing warning signs of severe dengue including severe abdominal pain, persistent vomiting, hematemesis, mucosal bleeding, respiratory distress, restlessness, or severe fatigue within the critical phase should be admitted and watched closely [15]. Admission should also be considered in the settings of pregnancy, extremities of age, or significant comorbidities. Still, most cases of dengue can be managed in the outpatient setting. Patients should be educated on symptoms of severe dengue and told to return due to the risk of rapid progression [15].

\section{Leptospirosis}

\section{Epidemiology and Transmission}

Leptospirosis is an aerobic spirochete transmitted by contact with infected animal urine through abrasions, mucous membranes, or ingestion of contaminated food or water. Those affected typically have a history of freshwater exposure such as wading through flood waters or participating in water sports. In the USA, only 100-150 cases are identified each year, of which 50\% are in Puerto Rico [19]. Cases have also been identified in Hawaii, the Pacific Coast, and the South. Internationally, leptospirosis can be acquired in most tropical regions with the highest risk in Southeast Asia [20].

\section{Signs and Symptoms}

Leptospirosis should be considered in patients with rapid onset fevers, myalgias, and headache with recent freshwater exposure or return from Southeast Asia. Incubation period is generally 5 to 14 days following exposure [21].

Leptospirosis consists of two phases [20]:

1. Phase one: Abrupt onset fevers, myalgias, and headache 1-3 weeks following exposure and lasting 2 to 9 days, concluding with cessation of fevers
- Conjunctival suffusion: Conjunctival injection without inflammatory exudates

- May occur in 15-80\% of cases and is highly specific [22-24]

- Other symptoms: Vomiting, diarrhea, hepatosplenomegaly, lymphadenopathy, pharyngitis, rash

2. Phase two, the "immune phase": Recurrent fever and potential development of complications:

- Pulmonary hemorrhage, ARDS, uveitis, optic neuritis, myocarditis, rhabdomyolysis, and Weil's disease (jaundice and nonoliguric renal failure)

\section{Management}

Diagnosis can be made from blood culture during phase one and urine culture during phase two $[19,25]$. Additional pathogen-specific testing is hospital dependent. Routine lab findings are nonspecific but can include thrombocytopenia, hypokalemia, hyponatremia, elevated amylase, transaminitis, and hyperbilirubinemia [20, 21]. An elevated creatinine kinase can be useful in distinguishing leptospirosis from other diseases as it is elevated in up to $50 \%$ of patients [56]. CSF can show lymphocytic or neutrophilic pleocytosis, mildly elevated protein, and normal glucose. CSF culture is generally positive in the first 10 days of illness [20]. Chest $\mathrm{x}$-ray should also be obtained for any respiratory symptoms due to risk of pulmonary hemorrhage and ARDS [20].

Most cases of leptospirosis are mild and can be managed outpatient with doxycycline $(100 \mathrm{mg})$ or azithromycin (500 mg) [19, 25]. Patients with pulmonary involvement, CNS infection, jaundice, renal failure, or age over 60 are at highest risk of death $[25,26]$ and should be admitted and given IV doxycycline (100 mg), penicillin (1.5 million IUs), or a third-generation cephalosporin [19, 25]. Until Rickettsia is ruled out, doxycycline is generally recommended as the initial treatment. In patients with severe disease, corticosteroids can be considered, but recent studies have conflicting data on their benefit $[27,28]$.

\section{Enteric (Typhoid) Fever}

\section{Epidemiology and Transmission}

Enteric fever is a broader term encompassing both typhoid fever caused by Salmonella enterica serotype Typhi and Paratyphoid fever caused by Salmonella enterica serotypes Paratyphi A, B, or C. While S. typhi is more common, 
S. paratyphi is becoming more prevalent particularly in South Asia and is not covered by the typhoid vaccines. Enteric fever is contracted through ingestion of contaminated food or water, and the highest risk is from visits to areas of poor sanitation. The CDC estimates 400 cases per year in the USA with over $70 \%$ of cases occurring in travelers returning from India, Bangladesh, or Pakistan [29•].

\section{Signs and Symptoms}

Enteric fever classically occurs in three stages:

1. Week 1: Fever, chills, bacteremia

2. Week 2: "Rose spots" and abdominal pain develop

3. Week 3: Hepatosplenomegaly, intestinal bleeding, and potential for ileocecal perforation

- In those hospitalized with enteric fever, incidence of perforation can be as high as $10 \%[30,31]$.

Enteric fever should be considered in patients who have traveled to an endemic area within the preceding 3 weeks and who are presenting with gastrointestinal symptoms accompanied by 3 or more days of fever. While most patients will complain of abdominal pain, diarrhea is not always seen, and patients can instead present with constipation. Other common symptoms include headache, cough, arthralgias, and myalgias [32].

\section{Management}

If enteric fever is suspected, workup should include complete blood count with differential, complete metabolic profile; coagulation screen; EKG; blood cultures; and stool culture. Findings that can help point to enteric fever include anemia, leukopenia with left shift (adults) or leukocytosis (children), elevated LFTs, high fever $\left(>40^{\circ} \mathrm{C}\right)$, and bradycardia [32].

Definitive diagnosis is made by blood culture, but this test has low sensitivity and will not provide a diagnosis in the ED. Therefore, patients with suspected enteric fever should be treated empirically based on clinical suspicion [57].

- Uncomplicated enteric fever: Oral azithromycin $1 \mathrm{~g}$ (followed by $500 \mathrm{mg}$ daily $\times 5-7$ days)

- Second line: Fluoroquinolone if acquired in a region with low resistance

- Severe illness with systemic symptoms requiring hospitalization: Ceftriaxone $2 \mathrm{~g}$ or cefotaxime $1-2 \mathrm{~g}$
- Patients with altered mentation or signs of shock should also be given dexamethasone $3 \mathrm{mg} / \mathrm{kg}$ as this has been shown to dramatically reduce mortality $[33,34]$.

- Recent travel to Pakistan: Carbapenem or azithromycin

- Ongoing outbreak of multidrug-resistant strain of S. typhi since 2016 [35]

\section{Traveler's Diarrhea}

\section{Epidemiology and Transmission}

Traveler's diarrhea is the most common illness seen in individuals traveling from developed to resource-limited regions [36], occurring in up to $40 \%$ of travelers [37, 38•]. Transmission is fecal-oral, most often by food and water in regions with suboptimal sanitation and hygienic practices [39]. The highest risk regions include South and Southeast Asia, Africa (excluding South Africa), South America, Central America, and Mexico. Food from street vendors and staying in "all-inclusive" lodgings are specific risk factors for developing the illness [40].

Most episodes occur between 4 and 14 days after arrival to a resource-limited region [41]. Acute illness is most frequently caused by bacteria but can also be caused by parasites or viruses. Worldwide, the most common cause is enterotoxigenic Escherichia coli (ETEC), followed by Salmonella, Campylobacter jejuni, and Shigella [39]. Practitioners should consider geographic variation, as Campylobacter species are more common than ETEC in Southeast Asia [42].

\section{Signs and Symptoms}

Classic traveler's diarrhea is defined as three or more unformed stools in $24 \mathrm{~h}$ plus at least one of the following: nausea, vomiting, abdominal pain, fever, or blood in stool. Symptoms are variable and partially dependent on the causative agent [39].

ETEC classically consists of malaise, anorexia, abdominal cramps followed by sudden onset watery diarrhea with very frequent stools, typically without blood or purulence. Patients may have a fever, nausea, or vomiting. Campylobacter or Shigella cause inflammatory diarrhea, which can present with similar symptoms but may progress to fever, tenesmus, or bloody diarrhea [39].

\section{Management}

Testing should include a basic metabolic panel to assess for dehydration or metabolic derangement. The determination of 
microbiologic agent is typically unnecessary as ETEC cannot be distinguished from nonpathogenic $E$. coli on routine stool cultures [43]. Whether or not to pursue further testing should be based on clinical judgment and will likely include a shared decision-making conversation with the patient. Stool testing in the ED is reasonable when patients present with severe diarrhea, bloody or mucoid stools, antibiotics in preceding 812 weeks, systemic illness, or symptom lasting longer than 10-14 days. Recommended tests include:

- Stool culture to evaluate for Campylobacter or Shigella.

- Hospital dependent tests for ETEC or Shiga toxin.

- Stool O\&P for Giardia lamblia, Cyclosporidium, Isospora, and other parasites.

- If recent antibiotic history, test for Clostridioides (Clostridium) difficile

- If the patient appears systemically ill, send blood cultures to evaluate for bacteremia, most commonly seen from Salmonella species (Typhi).

Consider admission for those patients with laboratory evidence of severe dehydration, acute kidney injury, need for electrolyte replacement and inability to tolerate orals, or systemic illness.

The treatment is typically symptomatic and supportive, as the vast majority of episodes is self-limited and resolves within three to 5 days. Although antibiotic stewardship is important, it is very reasonable to fill a 3-day antibiotic prescription prior to travel and start the antibiotic within 1-2 days of symptoms [39, 43]. Management includes the following:

- Fluid replacement, by mouth or intravenously.

- Antimotility agents such as loperamide or diphenoxylate can be helpful with those with frequent diarrhea.

- Antibiotics can reduce symptoms from several days to one or 2 days and are recommended for severe illness characterized by bloody or mucoid stool, or if symptoms substantially interfere with the purpose of travel [39, 43]. Options include:

- Azithromycin $1000 \mathrm{mg}$ once or $500 \mathrm{mg}$ daily for 3 days

Good choice if traveled to Southeast Asia (quinoloneresistant C. jejuni)

- Fluoroquinolones: Levofloxacin $500 \mathrm{mg}$ for one to 3 days or ciprofloxacin $750 \mathrm{mg}$ once or $500 \mathrm{mg}$ twice daily for 3 days

Falling out of favor due to greater awareness of side effects

- Rifaximin $200 \mathrm{mg}$ three times daily for 3 days or rifamycin $194 \mathrm{mg}$ twice daily for 3 days
Poorly absorbed but remain alternatives for patients in whom fluoroquinolones or azithromycin are not appropriate.

\section{Chikungunya}

\section{Epidemiology and Transmission}

Chikungunya is an arthropod-borne Alphavirus primarily transmitted by mosquito bites [44]. Interestingly, the name is derived from an African dialect meaning "stooped walk" due to the disease hallmark: debilitating joint and back pains. Chikungunya often occurs in outbreaks during the rainy season and has been seen globally in Africa, Asia, Europe, the Pacific Islands, and in the Americas [45].

Viremia occurs within a few days of infection, and the virus has a propensity to invade synovium, tenosynovium, and muscles [45]. The virus may linger in the joints for up to 2 weeks. Chronic arthritis develops in up to $60 \%$ of infected individuals [46].

\section{Signs and Symptoms}

Typically, symptoms start with fever and malaise lasting 35 days which are followed by polyarthralgias and dermatologic symptoms lasting 7-10 days [45]. However, arthralgias can persist for weeks, months, or even years. The rash is typically macular but can be patchy, diffuse, or pruritic. It often starts on the limbs and trunk and may involve the face. Arthralgias are the hallmark of chikungunya. The joint pain is typically bilateral and symmetric, affecting distal joints. The axial skeleton is involved in $34-52 \%$ of cases [46, 47]. Severe complications (respiratory failure, myocarditis, renal failure, hemorrhage, acute hepatitis, meningoencephalitis, acute flaccid paralysis, seizures) and death can occur, more often in elderly patients with medical comorbidities [44].

\section{Management}

Diagnosis can be made with chikungunya viral RNA RT-PCR within the first week (sensitivity $100 \%$ and specificity $98 \%$ ). If RT-PCR is negative or if the patient has had symptoms for 8 or more days, diagnosis is made by virus serology via ELISA or IFA. If testing for chikungunya, one should test for dengue virus and Zika virus as well [58]. Given the severe arthralgias associated with chikungunya, it may be prudent to rule out septic arthritis if significant effusion or asymmetry is present. Joint fluid analysis will be consistent with inflammatory arthritis [47].

Indications for admission include significant comorbidities or inability to ambulate. Treatment is primarily supportive 
with rest, fluids, and acetaminophen [59]. NSAIDs should not be used until dengue has been excluded [45].

\section{Zika}

\section{Epidemiology and Transmission}

Zika virus is an arthropod-borne flavivirus transmitted by mosquitoes. Transmission can also occur via the maternalfetal route, sexual intercourse (vaginal, anal, oral), or direct exposure to blood [48]. Outbreaks have occurred in Africa, Southeast Asia, the Pacific Islands, the Americas, and the Caribbean, most notably during the 2016 Olympic Games in Brazil $[49,50]$.

\section{Signs and Symptoms}

Approximately $20-25 \%$ of infected individuals have symptoms of infection, which are typically mild and last 2 to 7 days [51]. These include fever, pruritic rash, arthralgias, conjunctivitis, myalgias, headache, dysesthesia, and generalized weakness. Less commonly symptoms include abdominal pain, nausea, diarrhea, or mucous membrane ulcerations [52]. Zika has been implicated in serious neurologic complications such as congenital microcephaly, Guillain-Barré syndrome, myelitis, and meningoencephalitis [53].

\section{Management}

Zika can be diagnosed by PCR and serology testing. However, cross-reactivity with other flaviviruses is common, and testing is generally not recommended from the ED [54]. If labs are sent, CBC may show thrombocytopenia. Treatment is supportive with fluids and acetaminophen. Generally, patients will be discharged, and we recommend education surrounding transmission and pregnancy prevention. If the patient is suffering from a severe neurologic complication, we recommend brain/spine imaging, lumbar puncture, and admission.

\section{Conclusions}

The differential diagnosis in a febrile international traveler is broad, and in many cases, definitive diagnosis will not be made in the ED. In addition, while the CDC and WHO have useful guidelines for diagnosis and management, these tests and treatment might not be available in the emergency department. Therefore, one must be aware of alternative treatments particularly for severely ill patients. In an otherwise undifferentiated febrile traveler, basic labs can be drawn to narrow the differential and screen for risk of development of severe disease. Recognition of development of severe disease is critical as these patients have high risk of complications and death.

\section{Compliance with Ethical Standards}

Conflict of Interest The authors declare that they have no conflict of interest.

Human and Animal Rights and Informed Consent This article does not contain any studies with human or animal subjects performed by any of the authors.

\section{References}

Papers of particular interest, published recently, have been highlighted as:

- Of importance

1. Colucci B, Müller P. Evaluation of standard field and laboratory methods to compare protection times of the topical repellents PMD and DEET. Sci Rep. 2018;8:1-11. https://doi.org/10.1038/s41598018-30998-2.

2. Centers for Disease Control and Prevention (2019) CDC - Malaria Diagnosis \& Treatment (United States) - Treatment (U.S.). In: Centers for Disease Control and Prevention. https://www.cdc.gov/ malaria/diagnosis treatment/treatment.html. Jan 2020.

3. Fiore AE, Wasley A, Bell BP (2006) Prevention of hepatitis a through active or passive immunization: recommendations of the advisory committee on immunization practices (ACIP). In: Centers for Disease Control and Prevention. https://www.cdc.gov/mmwr/ preview/mmwrhtml/rr5507a1.htm. Accessed 7 Feb 2020.

4. Jackson BR, Iqbal S, Mahon B (2015) Updated recommendations for the use of typhoid vaccine - advisory committee on immunization practices. In: Centers for Disease Control and Prevention. https://www.cdc.gov/mmwr/preview/mmwrhtml/mm6411a4.htm. Accessed 7 Feb 2020.

5. Food and Drug Administration (2019) Dengvaxia. In: U.S. Food and Drug Administration. https://www.fda.gov/vaccines-bloodbiologics/dengvaxia. Accessed 7 Feb 2020.

6. Mace KE, Arguin PM, Lucchi NW, Tan KR. Malaria surveillance — United States, 2016. MMWR Surveill Summ. 2019;68:1-35 Provides epidemiologic information for malaria cases in the United States in 2016, the most recently reported year.

7. Akselrod H, Swierzbinski MJ, Zheng Z, Keiser J, Parenti DM, Simon GL. Characteristics and severity of disease among 100 cases of imported malaria seen at a U.S. university hospital, 2000-2017. Am J Trop Med Hyg. 2018;99:1511-7.

8. The World Health Organization. Guidelines for the treatment of malaria - 3rd edition. Geneva: World Health Organization; 2015.

9. Breman JG (2019) Clinical manifestations of malaria in nonpregnant adults and children. In: UpToDate. https://www.uptodate.com/ contents/clinical-manifestations-of-malaria-in-nonpregnant-adultsand-children sectionName $=$ Cerebral $\% 2$ Bmalaria $\&$ search $=$ malaria\&topicRef $=5667 \&$ anchor $=$ H6\& source $=$ see_link\#H6. Jan 2020.

10. Visser BJ, Wieten RW, Kroon D, Nagel IM, Bélard S, Vugt MV, et al. Efficacy and safety of artemisinin combination therapy (ACT) for non-falciparum malaria: a systematic review. Malar J. 2014;13: 463. 
11. Ballard S-B, Salinger A, Arguin PM, Desai M, Tan KR. Updated $\mathrm{CDC}$ recommendations for using artemether-lumefantrine for the treatment of uncomplicated malaria in pregnant women in the United States. MMWR Morb Mortal Wkly Rep. 2018;67:424-31.

12. U.S. Food and Drug Administration (2019) Current and resolved drug shortages and discontinuations reported to FDA. In: accessdata.fda.gov. https://www.accessdata.fda.gov/scripts/ drugshortages/dsp_ActiveIngredientDetails.cfm?AI=Quinidine\% 2BGluconate\%2BInjection\&st=d\&tab=tabs-2. Jan 2020.

13. Daily J (2019) Treatment of uncomplicated falciparum malaria in nonpregnant adults and children. In: UpToDate. https://www. uptodate.com/contents/treatment-of-uncomplicated-falciparummalaria-in-nonpregnant-adults-and-children?search= malaria\&source $=$ search result\&selectedTitle $=3 \sim 150 \&$ usage type $=$ default\&display_rank=3\#H345141709. Jan 2020.

14. Khuu D, Eberhard ML, Bristow BN, Javanbakht M, Ash LR, Shafir $\mathrm{SC}$, et al. Malaria-related hospitalizations in the United States, 2000-2014. Am J Trop Med Hyg. 2017;97:213-21.

15. World Health Organization (2019) dengue and severe dengue. In: World Health Organization. https://www.who.int/news-room/factsheets/detail/dengue-and-severe-dengue. Dec 2019.

16. Thomas SJ, Rothman AL, Srikiatkhachorn A, Kalayanarooj S (2019) Dengue virus infection: clinical manifestations and diagnosis. In: UpToDate. https://www.uptodate.com/contents/denguevirus-infection-clinical-manifestations-and-diagnosis?search= dengue\&source $=$ search_result\&selectedTitle $=1 \sim 96 \&$ usage_type $=$ default\&display_rank=1. Dec 2019.

17. Centers for Disease Control and Prevention (2019) Dengue: For Healthcare Providers. In: Centers for Disease Control and Prevention. https://www.cdc.gov/dengue/healthcare-providers/ index.html. Dec 2019.

18. Thomas SJ, Rothman AL, Srikiatkhachorn A, Kalayanarooj S (2019) Dengue virus infection: prevention and treatment. In: UpToDate. https://www.uptodate.com/contents/dengue-virusinfection-prevention-and-treatment? search $=$ dengue $\&$ source $=$ search $\_$result\&selectedTitle $=3 \sim 96 \&$ usage type $=$ default \&display rank=3\#H7. Dec 2019.

19. Centers for Disease Control and Prevention (2019) Leptospirosis: healthcare workers. In: Centers for Disease Control and Prevention. https://www.cdc.gov/leptospirosis/health_care_workers/index. html.

20. Day N (2019) Leptospirosis: epidemiology, microbiology, clinical manifestations, and diagnosis. In: UpToDate. https://www. uptodate.com/contents/leptospirosis-epidemiology-microbiologyclinical-manifestations-and-diagnosis? search= leptospirosis\&source $=$ search_result\&selectedTitle $=1 \sim 80 \&$ usage type $=$ default\&display rank $=1$. Dec 2019.

21. World Health Organization, International Leptospirosis Society. Human leptospirosis: guidance for diagnosis, surveillance and control. Geneva: World Health Organization; 2003.

22. Puca E, Pilaca A, Kalo T, Pipero P, Bino S, Hysenaj Z, et al. Ocular and cutaneous manifestation of leptospirosis acquired in Albania: a retrospective analysis with implications for travel medicine. Travel Med Infect Dis. 2016;14:143-7.

23. Mendoza MT, Roxas EA, Ginete JK, Alejandria NM, Roman AD, Leyritana KT, et al. Clinical profile of patients diagnosed with leptospirosis after a typhoon: a multicenter study. Southeast Asian J Trop Med Public Health. 2013;44:1021-35.

24. Abgueguen P, Delbos V, Blanvillain J, Chennebault JM, Cottin J, Fanello S, et al. Clinical aspects and prognostic factors of leptospirosis in adults. Retrospective study in France. J Infect. 2008;57: $171-8$.

25. Day N (2019) Leptospirosis: treatment and prevention. In: UpToDate. https://www.uptodate.com/contents/leptospirosistreatment-and-prevention?search=leptospirosis\&source=search
result\&selectedTitle $=2 \sim 80 \&$ usage_type $=$ default \&display_rank $=$ 2\#topicContent. Dec 2019.

26. Pappachan MJ, Mathew S, Aravindan KP, Khader A, Bharghavan PV, Kareem MM, et al. Risk factors for mortality in patients with leptospirosis during an epidemic in northern Kerala. Natl Med J India. 2004; 17:240-2.

27. Alian S, Asghari H, Najafi N, Davoudi A, Yazdani J. Corticosteroid in the treatment of moderate to severe thrombocytopenia due to leptospirosis. Iran Red Crescent Med J. 2014. https://doi.org/10. 5812/ircmj.16030.

28. Rodrigo C, Silva NLD, Goonaratne R, Samarasekara K, Wijesinghe I, Parththipan B, et al. High dose corticosteroids in severe leptospirosis: a systematic review. Trans R Soc Trop Med Hyg. 2014; 108:743-50.

29. Centers for Disease Control and Prevention. National Typhoid and Paratyphoid Fever Surveillance Annual Summary, 2015. In: Centers for Disease Control and Prevention; 2018. https://www. cdc.gov/typhoid-fever/reports/annual-report-2015.html. Dec 2019. Most recent surveillance data on Typhoid and Paratyphoid cases seen in the US.

30. Neil KP, Sodha SV, Lukwago L, O-Tipo S, Mikoleit M, Simington $\mathrm{SD}$, et al. A large outbreak of typhoid fever associated with a high rate of intestinal perforation in Kasese District, Uganda, 2008-2009. Clin Infect Dis. 2012;54:1091-9.

31. Gupta SP, Gupta MS, Bhardwaj S, Chugh TD. Current clinical patterns of typhoid fever: a prospective study. J Trop Med Hyg. 1985;88:377-81.

32. Ryan ET, Andrews J (2018) Epidemiology, microbiology, clinical manifestations, and diagnosis of enteric (typhoid and paratyphoid) fever. In: UpToDate. https://www.uptodate.com/contents/ epidemiology-microbiology-clinical-manifestations-and-diagnosisof-enteric-typhoid-and-paratyphoid-fever?search=typhoid\% 2Bfever\&source $=$ search_result\&selectedTitle $=1 \sim 114 \&$ usage type $=$ default\&display_rank=1\#H6. Dec 2019.

33. Hoffman SL, Punjabi NH, Kumala S, Moechtar MA, Pulungsih SP, Rivai AR, et al. Reduction of mortality in chloramphenicol-treated severe typhoid fever by high-dose dexamethasone. N Engl J Med. 1984;310:82-8.

34. Chisti MJ, Bardhan PK, Huq S, Khan WA, Khan AM, Sharifuzzaman SMA. High-dose intravenous dexamethasone in the management of diarrheal patients with enteric fever and encephalopathy. Southeast Asian J Trop Med Public Health. 2009;40:1065-73.

35. Chatham-Stephens K, Medalla F, Hughes M, Appiah GD, Aubert $\mathrm{RD}$, Caidi H, et al. Emergence of extensively drug-resistant Salmonella Typhi infections among travelers to or from Pakistan - United States, 2016-2018. MMWR Morb Mortal Wkly Rep. 2019;68:11-3.

36. Greenwood Z, Black J, Weld L, et al. Gastrointestinal infection among international travelers globally. J Travel Med. 2008;15:221.

37. Schlagenhauf P, Weld L, Goorhuis A, et al. Travel-associated infection presenting in Europe (2008-12): an analysis of EuroTravNet longitudinal, surveillance data, and evaluation of the effect of the pre-travel consultation. Lancet Infect Dis. 2015;15:55.

38. Stoney RJ, Han PV, Barnett ED, et al. Travelers' Diarrhea and Other Gastrointestinal Symptoms Among Boston-Area International Travelers. Am J Trop Med Hyg. 2017;96:1388 In a prospective cohort study, the authors examined the incidence of travelers diarrhea and report how many travelers were driven to take prescribed prophylactic antibiotics.

39. LaRocque R, Harris JB. Travelers' diarrhea: microbiology, epidemiology, and prevention. In: UpToDate. 2020. https://www. uptodate.com/contents/travelers-diarrhea-microbiologyepidemiology-and-prevention. Accessed 15 Jan 2020.

40. Hill DR, Beeching NJ. Travelers' diarrhea. Curr Opin Infect Dis. 2010;23:481. 
41. Steffen R, Collard F, Tornieporth N, et al. Epidemiology, etiology, and impact of traveler's diarrhea in Jamaica. JAMA. 1999;281:811.

42. Shah N, DuPont HL, Ramsey DJ. Global etiology of travelers' diarrhea: systematic review from 1973 to the present. Am J Trop Med Hyg. 2009;80:609.

43. LaRocque R, Harris JB. Travelers' diarrhea: clinical manifestations, diagnosis, and treatment. In: UpToDate. 2020. https://www. uptodate.com/contents/travelers-diarrhea-clinical-manifestationsdiagnosis-and-treatment. Accessed 15 Jan 2020.

44. Weaver SC, Lecuit M. Chikungunya virus and the global spread of a mosquito-borne disease. N Engl J Med. 2015;372:1231.

45. Wilson $\mathrm{M}$, et al. Chikungunya fever: epidemiology, clinical manifestations and diagnosis. In: Up To Date. 2020. https://www. uptodate.com/contents/chikungunya-fever-epidemiology-clinicalmanifestations-and-diagnosis. Accessed 15 Jan 2020.

46. Miner JJ, Aw Yeang HX, Fox JM, et al. Chikungunya viral arthritis in the United States: a mimic of seronegative rheumatoid arthritis. Arthritis Rheumatol. 2015;67:1214.

47. Schilte C, Staikowsky F, Couderc T, et al. Chikungunya virusassociated long-term arthralgia: a 36-month prospective longitudinal study. PLoS Negl Trop Dis. 2013;7:e2137.

48. Petersen LR, Jamieson DJ, Powers AM, Honein MA. Zika Virus. N Engl J Med. 2016;374:1552.

49. Fauci AS, Morens DM. Zika virus in the Americas-yet another Arbovirus threat. N Engl J Med. 2016;374:601.

50. Chen LH, Hamer DH. Zika virus: rapid spread in the Western hemisphere. Ann Intern Med. 2016;164:613.

51. Flamand C, Fritzell C, Matheus S, et al. The proportion of asymptomatic infections and spectrum of disease among pregnant women infected by Zika virus: systematic monitoring in French Guiana, 2016. Euro Surveill. 2017;22.

52. LaBeaud, AD. Zika virus infection: an overview. In: UpToDate. 2020. https://www.uptodate.com/contents/zika-virus-infection-anoverview. Accessed 16 Jan 2020.
53. World Health Organization. Consensus on causal link between Zika and neurological disorders. http://www.euro.who.int/en/healthtopics/emergencies/zika-virus/news/news/2016/04/consensus-oncausal-link-between-zika-and-neurological-disorders. 4 Jun 2016. Accessed 16 Jan 2020.

54. Centers for Disease Control and Prevention. Emergency preparedness and response: recognizing, managing, and reporting Zika virus infections in travelers returning from Central America, South America, the Caribbean, and Mexico. http://emergency.cdc.gov/ han/han00385.asp. 15 Jan 2016. Accessed 16 Jan 2020.

55. Tan KR, Arguin PM (2019) CDC yellow book 2020: health information for international travel. In: CDC yellow book 2020: health information for international travel. Oxford University Press, Oxford, New York, pp Chapter 4, Travel-Related Infectious Diseases, Malaria.

56. Johnson WD. Serum creatine phosphokinase in leptospirosis. JAMA. 1975;233:981.

57. Ryan ET, Andrews J (2019) Treatment and prevention of enteric (typhoid and paratyphoid) fever. In: UpToDate. https://www. uptodate.com/contents/treatment-and-prevention-of-enterictyphoid-and-paratyphoid-fever?search=typhoid\% 2Bfever\&source $=$ search_result\&selectedTitle $=2 \sim 114 \&$ usage type $=$ default\&display rank=2\#H14. Dec 2019.

58. Centers for Disease Control and Prevention. Chikungunya: information for healthcare providers. https://www.cdc.gov/ chikungunya/pdfs/CHIKV_Clinicians.pdf. Accessed on 16 Jan 2020.

59. Miner JJ, et al. Chikungunya fever: treatment and prevention. In: Up To Date. 2019. https://www.uptodate.com/contents/ chikungunya-fever-treatment-and-prevention. Accessed on 16 Jan 2020.

Publisher's Note Springer Nature remains neutral with regard to jurisdictional claims in published maps and institutional affiliations. 